\title{
Knowledge attitude and practices of childhood diarrhea and ORS administration in diarrhea amongst mothers of children below age 5 years: A hospital based cross-sectional survey
}

\author{
Naseem $\mathbf{A}^{1}$, Swetha $\mathbf{R}^{2}$ \\ ${ }^{1}$ Dr Altaf Naseem, Associate Professor, ${ }^{2}$ Dr Ravi Swetha, Senior Resident, Department of Paediatrics, DCMS, \\ Hyderabad, Telangana, India.
}

Address for Correspondence: Dr. Altaf Naseem, Email: docaltaf@rediffmail.com

\begin{abstract}
Introduction: Basic minimal information about care of children in diarrhea and ORS use is necessary for early recovery. To plan anti diarrheal program, its important to know the knowledge, beliefs, practices of diarrhea understanding and management including ORS; in community. Methods: A crosssectional survey of 300 serial mothers of under five children presenting to a hospital were enrolled and data regarding awareness of loose motion definition; ORS use, diet in diarrhea and beliefs and practices was collected by using a prevalidated questionnaire. Results: Most (74.59\%) mothers were in age group of 20-30 year old home makers. Only $31.97 \%$ wereaware of diarrhea leading to dehydration. Teething was considered a prime cause of diarrhea by $32.64 \%$ mothers. Rice based food was preferred in diarrheas by only $45.96 \%$ mothers. Only $35.26 \%$ knew that extra fluids are needed in diarrheas. Sixty six percent mothers had knowledge of home based ORS but only $22 \%$ knew correctly. ORS dose was not known to $89.5 \%$ of mothers. Conclusion: There is a serious need for modifying diarrhea control programs with community education.Incomplete information is likely to cause complications and delay in recovery.
\end{abstract}

Key words: ORS awareness, Diarrhea education

\section{Introduction}

Diarrhea is defined as passage of three or more watery stools in 24 hours. A loose stool is one that takes shape of the container. Diarrhea is a major killer disease in children and thus an important health problem in India, [1] Occupying at least $15 \%$ of hospital beds; diarrhea also emerges as a major economic burden to the country [2]. It is an important cause of malnutrition in children; primarily being related to improper absorption of food [3]. Poor food intake during diarrheal episodes is related to unhealthy practices of withholding food during motions, and anorexia vomiting associated with same [4]. Under five children in developing countries are known to get vicious cycle of diarrhea and malnutrition causing increasing morbidity and mortality related to diarrhea [5]. Mortality related to diarrhea is more common in 6 month to 1 year age, more so in a malnourished child [6]. Oral rehydration solution (ORS) being simplest economical, effective therapeutic

Manuscript received: $28^{\text {th }}$ April 2016

Reviewed: $11^{\text {th }}$ May 2016

Author Corrected; $27^{\text {th }}$ May 2016

Accepted for Publication: $15^{\text {th }}$ June 2016 intervention for prevention and treatment of dehydration has emerged as a magic potion in $20^{\text {th }}$ century in management of diarrheas $[1,7]$.

Despite this, it is felt that ORS propaganda is not adequately transferred to community resulting in inadequate, erratic or incomplete ORS therapy during dehydration [7].

Many wrong practices were noted in community when a child is hospitalized with diarrhea. Some parents stop food, stop milk or reduce solid intake. This study is planned to evaluate awareness, attitude and knowledge about diarrheas and ORS in a tertiary care hospital in Hyderabad.

\section{Objectives}

This study was aimed to assess awareness, attitudes and practices towards diarrhea; nutrition during an episode of diarrhea; ORS therapy. 


\section{Methods}

This study was conducted in the pediatric OPD and pediatric ward of Deccan College of Medical Sciences, which is a tertiary level hospital, catering mainly to the old city population of Hyderabad. Old City is an area near and around historical monument the Charminar. Most of the people attending our OPD are middle class and lower middle class. This planned prospective study was carried out from August 2008 to May 2010. Ethics committee permission was taken prior to study. All mothers who presented to pediatric or ward with an underfive child with diarrhea were enrolled. Total 300 consecutive mothers of less than 5 years old children attending our OPD and admitted under- 5 children for diarrhoea and related diseases were selected for this study. Written informed consent was taken.

For the study, a predesigned and pretested questionnaire was prepared comprising of nearly 30 questions, most of the questions were close ended. Besides literacy, socioeconomic status was also noted. Questions pertained to practices towards diarrhea, nutrition during diarrhea and awareness of oral rehydration therapy (ORT).A single interviewer interviewed all 300 mothers of the under-5 year children attending our OPD and those who are admitted under-5 children for diarrhea and related diseases. A total of 110 mothers were unaware of ORT, hence they were not included in extracting percentages from the questions pertaining to ORT.

It took nearly 15-20 minutes to finish one interview and on a single day, not more than 5 interviews were carried out. At the end of each interview, the mothers were provided with health education to improve their knowledge of diarrhea, nutrition during diarrhea and oral rehydration therapy, with practical demonstration of correct ORT preparation. Also, the mothers were handed over a health education pamphlet in Hindi and Telugu pertaining to diarrhea and ORT, to improve their knowledge and management skills in the future. The data was fed in Microsoft Excel and interpreted as mean and percentages.

\section{Results}

Most of the mothers interviewed were housewives (74.59\%) and were in the age group of 20-30 years (62.64\%) as shown in Table 1 and Figure 1 . A total of $78.67 \%$ of the mothers were literate and majority of them studied up to $10^{\text {th }}$ standard (26.64\%). Only 16 mothers (5.33\%) studied up to post graduate level (as shown in the table below) out of whom 4 were lecturers and 2 were advocates.(Table 2). Majority of the studied population belong to the socioeconomic class III (114)and class IV (70) as performed in accordance with the Kuppuswami scale. [Figure 2]

Table-1: Age distribution of study population.

\begin{tabular}{|c|c|c|c|}
\hline Sr. No. & Age(years) & Number & Percentage \\
\hline 1 & $<20$ & 20 & 05.94 \\
\hline 2 & $20-30$ & 190 & 62.60 \\
\hline 3 & $>30$ & 90 & 30.64 \\
\hline
\end{tabular}

$($ Total $\mathrm{No}=300)$

Table-2: Education profile of study population.

\begin{tabular}{|c|l|c|c|c|c|}
\hline Sr. no. & Education & \multicolumn{2}{|c|}{ Father } & \multicolumn{2}{c|}{ Mother } \\
\hline & & No. & \% & No. & 5.33 \\
\hline 1 & $\begin{array}{l}\text { Professional degree/ Post } \\
\text { graduate }\end{array}$ & 36 & 12.06 & 16 & 13.33 \\
\hline 2 & B.A., B. SC. Degree & 64 & 21.44 & 40 & 11.34 \\
\hline 3 & $\begin{array}{l}\text { Intermediate/Post High } \\
\text { School Certificate }\end{array}$ & 80 & 26.80 & 34 & 26.64 \\
\hline 4 & High School Certificate & 26 & 8.70 & 80 & 8.66 \\
\hline 5 & Middle School Certificate & 18 & 6.03 & 26 & 13.33 \\
\hline 6 & Primary School/ Literate & 22 & 7.36 & 40 & 21.33 \\
\hline 7 & Illiterate & 54 & 18.08 & 64 & \\
\hline
\end{tabular}


Regarding breastfeeding practices during diarrhoea, nearly $3 / 4^{\text {th }}$ of the mothers $(73.93 \%)$ said that they continued with breastfeeding during diarrhoea. 54 of them were in favour of stopping breastfeeding during episodes of diarrhoea. Many of them $(42.69 \%)$ strongly believed that solid foods worsen diarrhoea, hence it is to be stopped during diarrhoea. If it is required to give top-feeding, $92 \%$ of the mothers preferred bottles over cup and spoon (8\%). Even though $68 \%$ of the mothers were cleaning bottles by boiling in water, they were not practicing it regularly. Nearly $4 / 5^{\text {th }}$ of the mothers did not know correctly about homemade salt sugar solution. Though $80 \%$ of the mothers were aware of ORT, not all of them were practicing it (79.16\% of the 240 mothers) Of the 110 mothers who were not practicing ORT, 54.54\% were unaware of ORT. The most common reasons for not using ORT were that the child did not take ORT (27.27\% of the 55 mothers) and that the child had vomiting (9.09\%). [Figure 3]. More than half (59.98\%) of the mothers used ORT with the advice of medical personnel. This is followed by $21.06 \%$ with audio-visual media (TV/radio). Majority of the mothers $(62.02 \%)$ knew only one commercial form of ORS and $34 \%$ of the mothers do not remember any commercial form. Total of $50.55 \%$ of the mothers using ORT said that they do not wash their hands before preparing ORT.Majority of them $(114 / 190)$ started ORT after 6 to 12 hours of starting of diarrhoea. Of the 190 mothers who were using ORT, 69.50\% of them were wrongly preparing it with water, mostly over-dilution. Only $40.01 \%$ of the 190 mothers were using boiled and cooled water, $29.49 \%$ said that they used direct tap and bore-well water for the preparation of ORS.10 main parameters of questionnaire are described in Table 3.

Table-3: Awareness, Attitudes and practices.

\begin{tabular}{|c|l|c|}
\hline Sr no & Parameter & Percentage of mothers satisfying criteria \\
\hline 1 & Did not know the exact definition of diarrhoea & $96.01 \%$ \\
\hline 2 & Aware that diarrhoea leads to dehydration & $31.97 \%$ \\
\hline 3 & Teething as cause of diarhea & $32.64 \%$ \\
\hline 4 & Hot foods cause diarrhea & $20.67 \%$ \\
\hline 5 & Food contamination causes diarrhea & $29.32 \%$ \\
\hline 6 & Rice based feeds are best in diarrhea & $45.96 \%$ \\
\hline 7 & Oral fluids should be increased in diarrhea & $35.26 \%$ \\
\hline 8 & Aware of ORT but not practising it $(\mathrm{N}=240)$ & $79.16 \%$ \\
\hline 9 & Unaware of ORT N=110 & $54.54 \%$ \\
\hline 10 & Wrongly preparing ORT N=190 & $69.50 \%$ \\
\hline
\end{tabular}

158 of the 190 mothers said that they one or the other time used wrong commercial preparation like Sporolac/Lactrol as ORT. Nearly $90 \%$ of the mothers did not know exactly how much ORS is to be given with each loose stool.

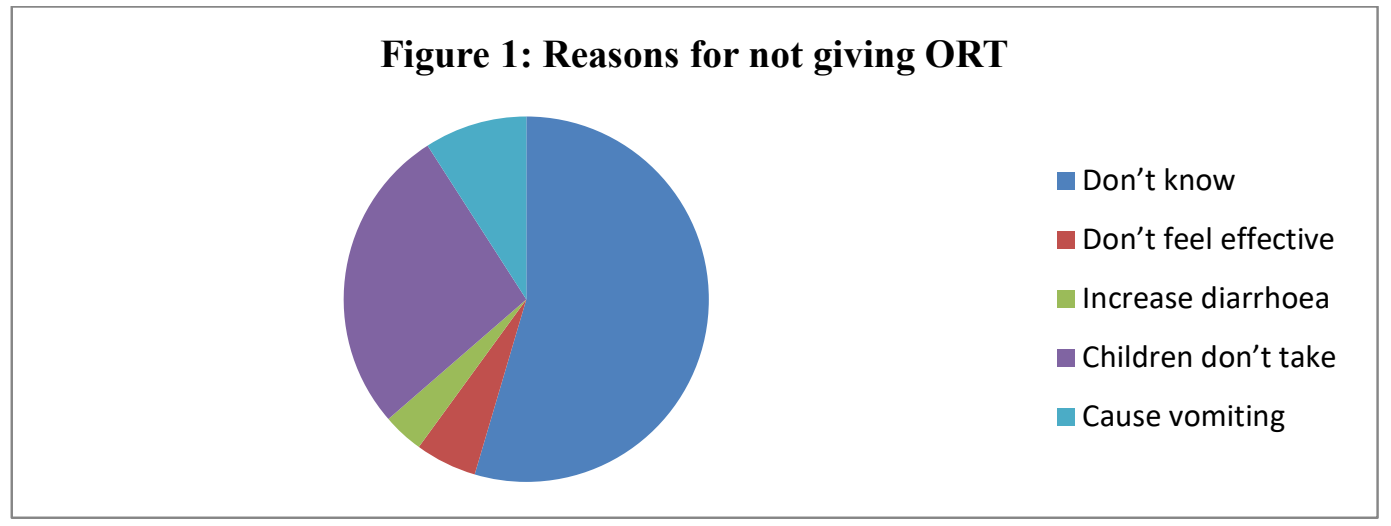

\section{Discussion}

Community knowledge, attitudes and practices is key for diarrheal research [8]. Despite decades of ORS propaganda and community education; globally maternal knowledge towards diarrhoea and ORS is inadequate [7,9]. The observation of the present study conducted in an urban population in the Old City of Hyderabad is an eye-opener for the local community healthcare providers. 
Majority of the population covered in the study belonged to Upper Middle (Class III; 37.96\%) and Lower (Class IV; 23.32\%) classes as per the modified Kuppuswami's Social Scale. Even though the percentage of literate mothers was high $(78.67 \%)$, their knowledge of diarrhoea was poor. In our study $96.01 \%$ did not know the exact definition of diarrhoea; in a Sudanese study, mothers could define diarrhea well but couldnot explain its causation [10].

The inexorable interaction of diarrhoea and malnutrition represents a dangerous web from which the infant, once entangled, has difficulty in escaping. Their nutritional practices during diarrhoea were influenced by social and cultural misbeliefs as $42.69 \%$ practiced stopping of solid food during diarrhoea. They had misconceptions like food causes diarrhoea (as given by $20.67 \%$ of the mothers). They considered wheat, eggs, meat, green mangoes and dates as "hot-food". In An Iranian Study, $30.3 \%$ mothers preferred to give just dough and enamelled rice while 20.35 preferred fruit juices [11] Another Indian study of 300 mothers mentioned 39\% mothers opting for rice milk as a diet in diarrhea [12]. In our study, it was encouraging to know that $45.96 \%$ of the mothers considered semisolid foods (rice-water and sabudana) as best foods during an episode of diarrhoea. Even though soft drinks are not recommended for consumption during diarrhoea, $7.35 \%$ thinks that commercial soft drinks are most suitable during diarrhoea for the prevention of dehydration.

In our study population, it was disheartening to see that only $31.97 \%$ of mothers were aware that diarrhoea leads to dehydration and nearly $3 / 4^{\text {th }}(71.86 \%)$ did not know signs of dehydration.

Many studies have shown increased incidences of diarrhoea related to bottle feeding; for example a study from west Bengal noted 26.08\% percent of bottle fed children suffering from diarrheas. [13] In our study, bottle feeding was found to be a rampant practice (92\%) and many of the mothers claimed to be washing the bottles. However, on further questioning, they were not done properly and routinely.

Even though commercial ORS preparations were easily available at various costs in pharmaceutical shops, $62 \%$ of the mothers knew only one commercial preparation and only 190 (63.37\%) mothers were practicing ORT. In the studied population, $20 \%$ were unaware of Oral Rehydration Therapy. The cause of not using ORT was mainly unawareness (30/150). 27.27\% mothers complained that their children did not like the taste of ORT and therefore did not use it. This is in contrast to a study from Nepal where $97.6 \%$ had information about ORS and 50\% could prepare ORS properly [14].

The success of ORT in acute diarrhoea is greatly influenced by the timing of initiation of ORT. A delay of more than 6 hours in starting ORT may not be very effective. In this study, $30 \%$ of the mothers did not start ORT within 6 hours of onset of diarrhoea. In a study by MU Khan in Bangladesh, hand washing technique was an effective interrupting method in the transmission of shigellosis even in insanitary environments. Half of our study population did not practice hand washing before preparing ORS [15].

Preparation of ORS in the correct method is as important as administering it correctly. Over-dilution and under-dilution both have their own risks (hyponatremia and hypernatremia respectively). 69.50\% of the study population was incorrectly diluting ORS. Most of them were mixing 1 teaspoon of ORS powder in 1 glass of water from the packet made for preparation in one litre. It was also quite surprising to see that many of the mothers (82\%) used Sporolac and Lactrol (probiotics which are commercially available in packet forms) as ORS.

A child loses about $50-100 \mathrm{ml}$ of water with each loose stool. Knowledge about how much ORS is to be given is very important in the success of ORT. There was a general ignorance about the quantity of ORS to be given with each episode of diarrhoea as $85 \%$ of the mothers were unaware of it.

Our study being hospital based; a broader community based study is likely to give a better idea of beliefs and practices. Also out study had limitation regarding data of socioeconomy and educational details of study population which may have great impact on knowledge, belief and practices.

\section{Summary and Conclusion}

In the present study, the awareness, attitude and practice of the mothers of under-five children towards diarrhoea, nutrition during diarrhoea episodes and knowledge of ORS were closely studied. Their knowledge and practices were inadequate and in some areas, grossly deficient. These practices were mainly influenced by social and cultural beliefs and usually have no scientific basis. This is true for both the literate and illiterate mothers. 
There is a grave need for the mothers in this area to be provided with proper health education, particularly those covering the topics of diarrhoea, proper sanitation habits, better nutritional practices and the proper use of ORS. Both government and non-government organisations should actively participate in the drive to deliver health education to the general population to decrease the burden of diarrhoeal diseases and its morbidity in this community.

\section{Funding: Nil, Conflict of interest: Nil \\ Permission from IRB: Yes}

\section{References}

1. Banerjee B, Hazra S, Bandyopadhyay D. Diarrhea management among under fives. Indian pediatrics. 2004 Mar;41(3):255-9.

2. World Health Organisation, Surveillance and Control of acute diarrhoeal disease. ERO reports Ser. No. 44, Copenhagen, 1981.

3. Moy RJ, de C MT, Choto RG, McNeish AS, Booth IW. Diarrhoea and growth faltering in rural Zimbabwe. European journal of clinical nutrition. 1994 Nov;48(11):810-21.

4. Patwari AK. Dietary management of diarrhoeal disease. Chap 12.

5. Patwari AK. Diarrhea and malnutrition interaction: Recent advances in paediatrics. Splvol 6 Chapt 11.

6. Yoon PW, Black RE, Moulton LH, Becker S.The effect of malnutrition on the risk of diarrheal and respiratory mortality in children $<2 \mathrm{y}$ of age in $\mathrm{Cebu}$, Philippines.The American journal of clinical nutrition. 1997 Apr 1;65(4):1070-7.

7. Datta V, John R, Singh VP, Chaturvedi P. Maternal knowledge, attitude and practices towards diarrhea and oral rehydration therapy in rural Maharashtra. The Indian Journal of Pediatrics. 2001 Nov 1;68(11):1035-7.

8. Bella H, Hussein AF, El-Mousan M, Danso KT, Sohaibani M, Khazindar MS. Knowledge, Attitudes and Practices related to Diarrhoea in Eastern Province, Saudi Arabia. Journal of family \& community medicine. 1994 Jan; 1(1):40-4.

9. Taha AZ. Assessment of mother's knowledge and practice in use of oral rehydration solution for diarrhea in rural Bangladesh. Saudi medical journal. 2002; 23(8):904-8.

10. Ahmed IS, Eltom AR, Karrar ZA, Gibril AR. Knowledge, attitudes and practices of mothers regarding diarrhoea among children in a Sudanese rural community. East African medical journal. 1994 Nov; 71(11):716-9.

11. Khalili M, Mirshahi M, Zarghami A, Rajabnia M, Farahmand F. Maternal Knowledge and Practice Regarding Childhood Diarrhea and Diet in Zahedan, Iran. Health Scope. 2013 May;2(1):19-24.

12. Kapoor P, Rajput VJ. Maternal knowledge, attitudes and practice in diarrhea.Indian Pediatr.1993;30(1):85-8.

13. Gupta A, Sarker G, Rout AJ, Mondal T, Pal R. Risk correlates of diarrhea in children under 5 years of age in slums of Bankura, West Bengal. Journal of global infectious diseases. 2015 Jan;7(1):23.

14. Jha N, Singh R, Baral D. Knowledge, attitude and practices of mothers regarding home management of acute diarrhoea in Sunsari, Nepal. Nepal Medical College journal: NMCJ. 2006 Mar;8(1):27-30.

15. Khan MU. Interruption of shigellosis by hand washing.Transactions of the Royal Society of Tropical Medicine and Hygiene. 1982 Jan 1;76(2):164-8.

\section{How to cite this article?}

Naseem A, Swetha R. Knowledge attitude and practices of childhood diarrhea and ORS administration in diarrhea amongst mothers of children below age 5 years: A hospital based cross-sectional survey. Int J Pediatr Res.2016;3(6):416420.doi:10.17511/ijpr.2016.i06.08. 